\title{
Amoxicillin haptenates intracellular proteins that can be transported in exosomes to target cells
}

Francisco J. Sánchez-Gómez*\#1, Juan M. González-Morena*1, Yolanda Vida ${ }^{2,3}$,

Ezequiel Pérez-Inestrosa ${ }^{2,3}$, Miguel Blanca ${ }^{4}$, María J. Torres ${ }^{4}$, Dolores Pérez-Sala ${ }^{\# 1}$

*Equal contributors

1. Department of Chemical and Physical Biology, Centro de Investigaciones Biológicas, CSIC, Madrid, Spain

2. Department of Organic Chemistry, University of Málaga, IBIMA, Campus Teatinos, s/n, 29071, Málaga, Spain

3. Andalusian Center for Nanomedicine and Biotechnology-BIONAND, Parque

Tecnológico de Andalucía, 29590, Málaga, Spain

4. Allergy Unit, IBIMA-Regional University Hospital of Málaga, UMA, Málaga, Spain

\#To either of whom correspondence should be addressed

Short title: Identification and fate of AX cellular targets 


\section{Abstract}

\section{Background}

Allergic reactions to $\beta$-lactams are amongst the most frequent causes of drug allergy and constitute an important clinical problem. Drug covalent binding to endogenous proteins (haptenation) is thought to be required for activation of the immune system. Nevertheless, neither the nature nor the role of the drug protein targets involved in this process is fully understood. Here we aim to identify novel intracellular targets for haptenation by amoxicillin (AX) and their cellular fate.

\section{Methods}

We have treated B-lymphocytes with either AX or a biotinylated analogue (AX-B). The identification of protein targets for haptenation by $A X$ has been approached by mass spectrometry and immunoaffinity techniques. In addition, intercellular communication mediated by the delivery of vesicles loaded with AX-B-protein adducts has been explored by microscopy techniques.

\section{Results}

We have observed a complex pattern of AX-haptenated proteins. Several novel targets for haptenation by $\mathrm{AX}$ in B-lymphocytes have been identified. AX-haptenated proteins were detected in cell lysates and extracellularly, either as soluble proteins or in lymphocyte-derived extracellular vesicles. Interestingly, exosomes from AX-B-treated cells showed a positive biotin signal in electron microscopy. Moreover, they were internalized by endothelial cells, thus supporting their involvement in intercellular transfer of haptenated proteins.

\section{Conclusions}

These results constitute the first identification of AX-mediated haptenation of intracellular proteins. Moreover, they show that exosomes can constitute a novel 
vehicle for haptenated proteins, and raise the hypothesis that they could provide antigens for activation of the immune system during the allergic response. 
Key words

Amoxicillin, cellular protein targets, drug adducts, exosomes, haptenation 


\section{Introduction}

$\beta$-lactams are the antibiotics most commonly prescribed and most frequently involved in hypersensitivity reactions induced by specific immunological mechanisms, which represent a growing impedance for their clinical use (1-3). Due to the current prescription tendencies, amoxicillin (AX) provokes most allergic reactions (AX) (4), whereas reactions to clavulanic acid are on the rise $(5,6)$. Frequently, $\beta$-lactams induce immediate hypersensitivity reactions mediated by specific IgE antibodies (7), that must be preceded by a sensitization phase where antigen presenting cells (APC) uptake and process the antigen and finally produce the class switching of lymphocytes $B$ to $\lg E$ production (8). There are three main hypotheses on the mechanisms of antigen presentation. In the "hapten hypothesis" (9), the drug, or hapten, binds covalently to endogenous proteins that are processed and presented by cells (10). The "danger signal hypothesis" proposes that both, drug-induced cytotoxic damage and its immune recognition, contribute to the allergic reaction (11). Finally, the "P-I (pharmacological interaction) concept" $(12,13)$ proposes high-affinity non-covalent interactions between the drug and immune receptors such as MHC or TCR. Interestingly, in certain cases, IgE from allergic patients does not recognize $A X$ alone or conjugated to exogenous structures. This supports the importance of endogenous structures in the formation of the antigenic determinants involved in allergic responses to $A X$, and thus in $A X$ recognition $(14,15)$. Therefore, efforts are been devoted to the identification of $\mathrm{AX}$-carrier proteins and their potential role in the allergic process. Most studies to date have been directed to the identification of AX-target proteins in plasma or serum (16). Early studies reported penicillin addition to specific lysine residues on HSA (17), and later transferrin was identified as an ampicillin target. Subsequently, circulating albumin-hapten complexes formed by piperacillin, benzylpenicillin and other $\beta$-lactams have been detected (18-20). In recent studies we identified HSA, transferrin and light and heavy chains of immunoglobulins, as targets for haptenation by $A X$ in 
serum in vitro (7), with HSA Lys190, being the only site for haptenation identified in ex vivo samples (21). In theory, drugs in general and $A X$ in particular could also form adducts with cellular elements, either in the circulation or along the administration route. Nevertheless, the identity and fate of the cellular targets of AX are poorly understood. To this aim, we have developed and validated immunological methods using specific anti-AX antibodies (22), as well as a biotinylated AX derivative which facilitates the detection of adducts with superior sensitivity, using analog concentrations closer to the expected pharmacological AX concentrations (23). Here we have addressed the identification and subcellular distribution of AX-haptenated proteins in Bcells, a cell type that can be involved in antigen presentation $(24,25)$. Our results show for the first time that several intracellular proteins are selectively haptenated by $A X$ and secreted both in soluble as well as in extracellular vesicular (EV) fractions, which can participate in the intercellular transfer of AX-adducts. Taken together, these results provide a whole set of novel structures potentially involved in sensitization to AX, as well as new working hypothesis for the development of drug allergy through the vehiculization and/or processing of drug adduct-bearing exosomes. 


\section{Materials and methods.}

Reagents

AX-B was prepared as previously described (23), Amoxicillin (Clamoxyl) was from GlaxoSmithKline. Enhanced chemical luminescent reagent (ECL) and Horseradish Peroxidase (HRP)-Streptavidin were from GE Healthcare. Sypro-Ruby and Ampholytes were from BioRad. Acetone was from Merck. Neutravidin beads were from Thermo Fisher. lodoacetamide, protein G-agarose, 4',6-diamidino-2-phenylindole dihydrochloride (DAPI), N-hexanoyl-D-sphingosine (C6 ceramide), Nhexanoyldihydrosphingosine (dihydroceramide C6), GW4869, penicilin G,streptavidinGold particles of $10 \mathrm{~nm} \varnothing$, anti-HSP70 and anti- $\beta$-Actin were from Sigma. Fluorescein5-isothiocyanate (FITC), Alexa-488 streptavidin, Texas Red-streptavidin (TXRStreptavidin) and anti-rabbit-Alexa 647 were from Molecular Probes. Antibodies against a-enolase (sc-100812), RhoGDI (sc-360) and ICAM-1 (sc-7891) were from Santa Cruz Biotechnology and anti-penicillin from AbDSerotec.

\section{Cell culture and treatments}

The lymphocytic B cell line RPMI 8866 was from Sigma-Aldrich. Bovine aortic endothelial cells (BAEC) were from Lonza. Cells were cultured in RPMI 1640 (Gibco) supplemented with $10 \%(\mathrm{v} / \mathrm{v})$ fetal bovine serum (FBS) or $10 \%$ calf serum, respectively, without antibiotics in a humidified atmosphere. For B-lymphocyte treatments, $8 \times 10^{7}$ cells per experimental condition were washed 4 times with $10 \mathrm{ml}$ of serum-free medium to exhaustively remove serum proteins, resuspended in $3 \mathrm{ml}$ of serum-free medium and treated overnight $(\mathrm{o} / \mathrm{n})$ with $\mathrm{AX}$ or $\mathrm{AX}-\mathrm{B}$ at the indicated concentrations, before collection of cells and conditioned medium. In experiments to assess the secretion of AX-B-haptenated proteins, excess AX-B was removed by washing cells with serum- 
free medium. Cells were then resuspended in $3 \mathrm{ml}$ of serum-free medium and cultured for additional $24 \mathrm{~h}$ before cells and conditioned medium collection. Cell viability was assessed by trypan blue dye exclusion.

\section{Sample preparation}

Cells and conditioned medium were separated by centrifugation at $1200 \times \mathrm{g} 5 \mathrm{~min}$ at 4 ${ }^{\circ} \mathrm{C}$. Cells were lysed in homogenization buffer as previously described (26). The conditioned medium was fractionated by sequential centrifugation. The extracellular membrane fraction was obtained by centrifugation at $15000 \times \mathrm{g}, 5 \mathrm{~min}$ at $4^{\circ} \mathrm{C}$. The resulting supernatant was centrifuged at $200000 \times \mathrm{g}, 30$ min at $4{ }^{\circ} \mathrm{C}$ to obtain the $\mathrm{EV}$ fraction (pellet) plus extracellular soluble proteins (supernatant). EV pellets were resuspended in $60 \mu \mathrm{l}$ of PBS. Extracellular soluble proteins were subjected to ultrafiltration with Amicon Ultra-4 10K filters to remove unreacted $A X$ or $A X-B$, and concentrated down to a final volume of $2 \mathrm{ml}$ (conditioned medium Soluble Proteins).

\section{Western blot and detection of adducts between $A X$ or $A X-B$ and cellular proteins}

Cell lysates ( $30 \mu \mathrm{g}$ of protein estimated by the BCA method), $30 \mu$ l of membrane fraction, $30 \mu \mathrm{l}$ of exosomes and $60 \mu \mathrm{l}$ of extracellular Soluble Proteins were analyzed by SDS-PAGE and Western blot as described (26). For 2D electrophoresis, cell lysates (200 $\mu \mathrm{g}$ of protein), $60 \mu \mathrm{l}$ of EVs or $1.8 \mathrm{ml}$ of Soluble Proteins fraction were precipitated with ice-cold acetone (27), dried, resuspended with $280 \mu$ l of 2D sample buffer $(23,28)$, and analyzed in duplicate. One gel was transferred to Immobilon-P membrane and the other stained with Sypro Ruby. AX-B-protein adducts were detected by blotting membranes with HRP-Streptavidin. AX-modified proteins were detected by incubation with anti-AX monoclonal antibody AO3.2 (7), and proteins of interest with the corresponding antibodies using ECL detection. 
Proteomic analysis

After 2D electrophoresis, spots positive for AX or AX-B were located in the Sypro-Ruby stained gels, processed by trypsin digestion and analyzed by MS (7). MS data were used to interrogate the NCBI non-redundant protein database SwissProt 2014_03 (542782 sequences; 193019802 residues) using MASCOT software 2.3 (Matrix Science).

Purification of AX-B modified proteins by avidin-based chromatography.

Biotinylated proteins from $500 \mu$ l of extracellular Soluble Proteins fraction from control and AX-B treated cells were purified by adsorption onto Neutravidin beads under stringent conditions (28). Blots were developed with HRP-Streptavidin or antibodies against the proteins of interest.

Protein immunoprecipitation

The direct modification of the proteins of interest was assessed by immunoprecipitating samples from control or AX-B-treated cells with specific antibodies and detection of the associated biotin signal as described (29).

\section{Electron microscopy}

EVs were analyzed by electron microscopy (EM) (30). Briefly, $5 \mu$ l of exosomes fixed with 2\% PFA were adsorbed onto Formvar-carbon coated EM grids, washed, fixed and contrasted. Then, samples were blotted with methyl cellulose. Grids were inspected for gold particles associated to EV under a JEOL 1230 electron microscope operated at $100 \mathrm{kV}$. Micrographs were recorded at 40000x magnification. Associated biotin was detected by EVs incubation with Streptavidin-Gold prior to fixation. 
Fluorescent detection of $A X-B$ incorporation into $B$-cells

RPMI 8866 cells $\left(5 \times 10^{5}\right)$ in glass-bottom $35 \mathrm{~mm}$ cell culture dishes (MAT-TEK

Corporation) were treated with $0.5 \mathrm{mg} / \mathrm{ml} \mathrm{AX-B} \mathrm{o/n} \mathrm{in} \mathrm{serum-free} \mathrm{RPMI1640,} \mathrm{washed}$ with PBS and fixed with 4\% PFA. Fixed cells were permeabilized with $0.1 \%$ Triton X100 in PBS, blocked with 3\% BSA in PBS and incubated with Alexa-488 streptavidin 1:500 for $1 \mathrm{~h}$ at r.t. Nuclei were stained with DAPI. AX-B incorporation into Blymphocytes was visualized by confocal fluorescence microscopy in a Leica TCS SP2 confocal laser spectral microscope, as described (31).

Internalization of $A X-B$-modified EVs into BAEC

EVs isolated from control or AX-B-treated cells were resuspended in PBS and consecutively labeled with $100 \mu \mathrm{M}$ FITC in PBS for $1 \mathrm{~h}$ at r.t. as a tracer, and Streptavidin-Texas Red (1:200) for 30 minutes at r.t. to specifically detect biotin moieties. Labeled EVs were added to the incubation medium of BAEC cultured in glass-bottom dishes for $3 \mathrm{~h}$. Cells fixed as above were subjected to immunofluorescence detection of RhoGDI, as a cytoplasm marker, as described (28). Incorporation of EVs into BAEC was assessed by confocal fluorescence microscopy and analyzed for each section.

\section{Statistics}

Results are represented as mean \pm SEM of at least 3 independent experiments.

Differences between experimental conditions were analyzed by non-parametric test when normality tests were not supported by the data. For normal data population, ANOVA statistical analysis was applied. Experimental conditions were considered different when $p<0.05$. 


\section{Results}

$\beta$-lactams bind selectively to intracellular proteins.

Current knowledge on intracellular AX targets is limited. We recently showed that the pattern of AX-haptenated proteins is cell-type-dependent (23). To identify AX cellular targets we chose a lymphocytic B cell line, RPMI 8866, because B lymphocytes can act as APC in the allergic response (32) and this cell line possesses the molecular machinery for antigen presentation (33). Incubation of B-lymphocytes with Penicillin G, AX or AX-B generated protein adducts, although with non-superimposable patterns (figure 1A). AX-B allowed the detection of protein adducts with higher sensitivity. Moreover, we confirmed AX-B entry into cells by confocal microscopy (figure 1B), which showed a particulate localization of the biotin signal compatible with vesicular traffic and processing.

Detection of AX-B haptenated proteins in B-lymphocytes.

To obtain a global perspective of $\mathrm{AX}$ adduct formation in the cellular context we analyzed several fractions from control and AX-B-treated B-cells and their conditioned medium. We detected a wide number of haptenated proteins in 1D gels of the various fractions, with common or selective biotin-positive bands, marked by arrow heads and asterisks, respectively (figure 2A). Several bands were present in extracellular fractions (EVs and soluble proteins), suggesting that some modified proteins could be secreted from cells (see below). To confirm fractionation adequacy, blots were probed with antibodies against proteins characteristic of each compartment: anti-ICAM-1 (immune cell membranes and EVs (34)), anti-actin (cytoskeleton), anti-a-enolase (cytoplasm) and anti-Rho-GDI (cytosol).

AX-B-haptenated proteins were further analyzed by IEF 2D SDS-PAGE of the Soluble Extracellular Proteins (figure 2C). Staining with HRP-streptavidin showed multiple 
specific biotin-positive spots in AX-B samples, whereas only endogenous biotinylated proteins were present in control samples, consistent with the results of $1 \mathrm{D}$ gels.

$A X$ and $A X-B$ share a closely related haptenation pattern.

To exclude potential interferences of the biotin moiety with the haptenation process, we explored whether $A X$ and $A X-B$ induced similar haptenation patterns before proceeding to the identification of $A X-B$-haptenated proteins. Figure 2B shows the patterns of $A X-$ haptenated proteins obtained by immunological detection, which as shown above, requires treating cells with higher concentrations of antibiotic. This approach confirmed the presence of AX-haptenated proteins in all fractions obtained, with a distribution similar to that obtained for AX-B. Validation of the fractions obtained was carried out as in figure $2 \mathrm{~A}$.

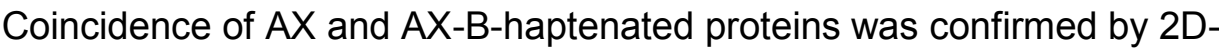
electrophoresis and immunoblot of the soluble extracellular fraction. Equivalent spots positive for $A X-B$ or $A X$ are depicted by circles in figure $2 \mathrm{C}$. The patterns of total protein staining with Sypro-Ruby of soluble fractions from AX and AX-B samples were also superimposable.

These results support the use of AX-B as a "bona fide" tool to study protein haptenation by AX.

Identification of proteins haptenated by $A X / A X-B$.

To identify the protein targets for haptenation by $A X$ and $A X-B$, the spots marked in figure 2 were analyzed by peptide fingerprinting by MALDI-TOF MS. The main targets identified (detailed in Table 1) include HSP70, EF-2, actin and $\alpha$-enolase. Although all of them are fairly abundant proteins, the biotin signal observed for each protein did not directly correlate with their abundance, indicating a certain degree of selectivity. Neither 
BSA, nor other components of bovine serum were identified in this screen, thus showing the efficacy of the washing steps.

Avidin-based affinity chromatography followed by Western blot (figure $3 \mathrm{~A}$ ) confirmed the presence of EF-2, HSP-70, $\beta$-Actin and $\alpha$-enolase in the fraction eluted from avidin, but only from AX-B-treated cells, indicating that these proteins are modified by AX-B. Moreover, immunoprecipitation showed positive biotin signals associated with EF-2, $\alpha-$ enolase and HSP70 (figure 3B). Haptenation of actin could not be evaluated by this approach due to poor performance of the antibody. Taken together, our results unequivocally show the haptenation of intact cellular proteins by $A X-B$, as well as their presence in the conditioned medium of AX-B-treated B-lymphocytes.

AX-haptenated proteins are actively and selectively secreted by B-lymphocytes.

Because haptenated proteins found in the extracellular medium of B-lymphocytes could behave as "allergenic messengers", we explored whether they were haptenated intracellularly, and subsequently secreted, or extracellularly. For this, AX-B-treated Blymphocytes were extensively washed to remove the extracellular proteins and any unreacted $A X-B$, and incubated with fresh medium o/n, after which, conditioned medium was collected and analyzed to detect released intracellularly-haptenated proteins. This showed that haptenated proteins were released from cells with time (figure 4A). Finally, cells were lysed and conditioned medium was fractionated as above. This confirmed the presence of haptenated proteins both in EVs and in extracellular soluble proteins (figure 4B, upper panels). A role for cytotoxicity in protein and/or vesicle release seems unlikely since cell viability was not affected by treatments or cell culture conditions (Ct: $2.92 \% \pm 0.57 \%$; AX-B: $2.9 \% \pm 1.43 \%$, mean \pm SEM of three determinations). Moreover, the patterns of markers for the different fractions do not support the non-specific release of cytosolic proteins, like RhoGDI, which is not detectable in the extracellular soluble fraction, whereas a-enolase appears selectively 
enriched in this fraction, consistent with a potential active secretion process (figure 4B, lower panels).

This supports that proteins can be haptenated by AX-B intracellularly and exported either as EVs cargo or in soluble form. The nature of EVs bearing AX-B-haptenated proteins was studied by EM (figure 4C), which showed vesicles with size and morphology typical of exosomes (35). Exosome secretion can be regulated by multiple mechanisms, including those dependent on the complex endosomal sorting machinery, tetraspanins and the lipid composition of the endosomal membranes. Treatment with C6 ceramide or the neutral sphingomyelinase inhibitor GW4869 induces or represses exosome secretion, respectively (36). Interestingly, we observed that EVs fractions from cells treated with C6 ceramide displayed a higher content of AX-B-haptenated proteins, as well as of the exosomal markers ICAM-1 and HSP70 (figure 4D). Dihydroceramide C6, which is structurally similar to C6 ceramide but does not stimulate exosomal release, was without effect. Conversely, EVs from B-lymphocytes treated with GW4869 showed reduced levels of AX-B-haptenated proteins and ICAM-1 (figure 4D). Therefore, these results point to a direct relationship between the abundance of AX-B-haptenated proteins in EVs and exosome release.

Identification of $A X$-haptenated proteins in exosomal fractions

Analysis of EVs by 2D-electrophoresis showed that although the pattern of biotinpositive spots was not identical to that of soluble proteins, the main spots were coincident (figure 4E). Identification of these AX-B targets by proteomic techniques (Table 1) and Western blot of the membranes from 2D gels (data not shown), confirmed that $\alpha$-enolase, EF-2 and HSP70 were also secreted in exosomes as AX-Bhaptenated proteins. Incorporation of AX-B into exosomes was directly evidenced by incubation of secreted EVs with streptavidin-gold beads and EM (figure 5A). These 
results unveil the relevance of exosomes as carriers of proteins haptenated intracellularly.

Nevertheless, exosomes from various cell types circulate in plasma in health and disease $(37,38)$. Therefore, besides the serum proteins previously identified as AXcarriers, components of exosomes already present in the circulation could also be haptenated by $A X$ or other drugs. Thus, we explored the formation of adducts between $A X-B$ and proteins in exosomes from control cells in vitro, and compared the pattern of haptenated proteins with that of exosomes secreted by AX-B-treated cells (Fig. 5B). AX-B bound to proteins in isolated exosomes, although the profile of biotin-positive polypeptides showed differences in the intensity of some bands compared to that of secreted exosomes. These observations suggest that exosomes may be relevant carriers of haptenated proteins by various mechanisms.

Haptenated proteins packed in exosomes can be imported by target cells.

Finally, we evaluated the potential role of exosomes as intercellular carriers of AX-Bhaptenated proteins. For this, EVs obtained from control or AX-B-treated Blymphocytes as in figure 4C were labeled with FITC, as tracer, and incubated with TXR-streptavidin, to specifically visualize the biotin moiety. These EVs were added to the culture medium of BAEC as a relevant cellular model, since aortic endothelial cells have been shown to act as "non-professional" APC (39), as other endothelial cell types (40-42). Remarkably, confocal microscopy revealed fluorescent vesicles at different stages of internalization, appearing either at the cell periphery, or in perinuclear Iocalization, compatible with endosomal compartmentalization (figure 5C). Importantly, EVs from control RPMI8866 cells showed only green fluorescence (FITC labeling), whereas EVs from AX-B treated RPMI8866 cells showed also a distinctive red fluorescence, reporting the presence of AX-B-haptenated proteins. These results show that EVs from B-lymphocytes, carrying AX-B-haptenated proteins had been 
incorporated into endothelial cells. Altogether these results represent the first evidence of AX-haptenated proteins packed in exosomes and delivered into target cells, raising the possibility that exosome-mediated hapten delivery may also contribute to the modulation of the allergic response to $A X$. 


\section{Discussion}

It is commonly accepted that due to its small size, AX antigenicity should be conditioned to haptenation of the patient's proteins (9). However, the responsible antigenic determinants and the mechanisms involved remain unclear (6). Importantly, clinical data suggest that structural determinants from the carrier protein(s) may also play a role in the recognition of AX-derived structures by the patient $\lg E$ (14). Therefore, to achieve better diagnostic and potentially therapeutic strategies, it is important to characterize AX carriers in detail. Besides the serum proteins identified as AX-targets $(7,23)$, cellular components could also be haptenated by $A X$.

Here we report the first identification of intracellular targets haptenated by AX, their active secretion either as soluble proteins or packed in exosomes, and the incorporation of the carrier vesicles into target cells. These proteins represent novel candidates for diagnostic clinical markers. Remarkably, AX-allergic patients can show a selective response to $A X$ or a broader response towards other $\beta$-lactams (43). Identification and characterization of the common and specific targets for various $\beta$ lactams could afford insight into the mechanisms underlying the selectivity of the allergic response.

Notably, the pattern of targets modified by $A X$ and AX-B were quasi identical. This, together with their similar reactivity (23), has allowed us to use AX-B as a "bona fide" tool to identify targets for haptenation by $\mathrm{AX}$, taking advantage of its higher sensitivity. Targets reported in this work are fairly abundant proteins. Further work will be needed to identify less abundant proteins potentially relevant for the allergic process or of diagnostic interest.

Importantly, we have detected intact haptenated proteins in cells conditioned medium and determined that haptenation can take place inside cells and modified targets can 
subsequently be secreted either as soluble proteins or in EVs. To the best of our knowledge this is the first study showing secretion of drug-protein adducts in exosomes, which could have important consequences for drug adverse effects, particularly, $\beta$-lactam-induced allergic reactions. Most interestingly, a common set of AX-targets including EF-2, HSP70 and a-enolase are secreted from cells both in soluble and exosomal fractions. The selective modification of these targets may imply that they possess structural features favorable for AX binding. In future works we will explore these factors and confirm whether these proteins are also haptenated by $A X$ in other cell types or in the circulation. Interestingly, HSP70 and a-enolase from several species are well-known allergenic proteins for humans (44-46). It would be tempting to speculate that drug modification of the endogenous proteins may render them allergenic as well.

Importantly, modulation of exosome shedding impacts the presence of AX-Bhaptenated proteins in EVs, indicating that exosomes play a key role in transport of AXB-modified proteins. Here we have confirmed that exosomes carrying AX-B-modified structures can be incorporated into target cells, thus transferring their "information". Although the fate of internalized exosomes is beyond the scope of this study, theoretically they could supply preformed MHC-peptide complexes or undergo degradation yielding haptenated peptides for antigen presentation (47).

Exosomes act as "messenger" vesicles involved in intercellular transfer of biological molecules $(48,49)$, modulating physiological and pathophysiological processes $(50$, 51). Therefore, haptenated proteins could putatively be transported by these vesicular carriers to induce the allergic response in distant cells. Our results show that haptenation can also occur in isolated exosomes in vitro. Consequently, the possibility exists that $A X$ could haptenate proteins present in circulating exosomes derived from 
diverse cell types (50-52). This widely opens the array of potential candidates contributing to the formation of $A X$ antigenic determinants.

Therefore, our results highlight a vesicular pathway for delivery of exosomeencapsulated, newly identified AX-haptenated proteins that could potentially contribute to the allergic response. 


\section{Acknowledgements}

We are indebted to María Jesús Carrasco for her invaluable technical support. We thank the staff of Centro de Investigaciones Biológicas Cellular Culture, Electron Microscopy, Confocal Microscopy and Proteomic facilities, as well as the Proteomic Unit from Universidad Complutense de Madrid.

\section{Funding}

This work was supported by grants SAF2015-68590R, SAF2012-36519 from MINECO, Spain and RIRAAF/RD12/0013/0008 from ISCIII to D.P-S.; by grants CTQ2013-41339-

P from MINECO, Spain and RD12/0013/0003 from ISCIII to E. P-I.; and by grants PI12/02529 and PI15/01206 from MINECO- grant cofunded by ERDF, Spain, RIRAAF/RD12/0013/0001 from ISCIII, CTS-06603 from Junta de Andalucía , grant cofunded by the ERDF, PI-0545-2010, PI-0551 and PI-0699-2011 from Junta de Andalucía to M.J.T and M.B.

\section{Author contributions}

FSG and JMGM performed experiments and analyzed data

YV and EPI prepared and characterized biotinylated amoxicillin and critically read the manuscript.

MB and MJT critically read the manuscript and provided insightful information and discussion valuable for design and interpretation of data.

FSG and DPS designed the study, analyzed data and wrote the manuscript.

\section{Conflict of interest}

The authors of the manuscript state that there are no conflicts of interest 


\section{References}

1. Acar JF, Kaplan EL, O'Brien TF. Monitoring and management of bacterial resistance to antimicrobial agents: a World Health Organization symposium. Geneva, Switzerland, 29 November-2 December, 1995. Clin Infect Dis 1997;24 Suppl 1:S1-176. 2. Blanca M, Torres Jaen MJ, Mayorga C, Padial A. Penicillin allergy is a global problem: the European experience. J Allergy Clin Immunol 2003;112(5):1014-1015; author reply 1015-1016.

3. Macy E. Penicillin and beta-lactam allergy: epidemiology and diagnosis. Curr Allergy Asthma Rep 2014;14(11):476.

4. Blanca M, Mayorga C, Torres MJ, Warrington R, Romano A, Demoly P, et al. Side-chain-specific reactions to betalactams: 14 years later. Clin Exp Allergy 2002;32(2):192-197.

5. Torres MJ, Ariza A, Mayorga C, Dona I, Blanca-Lopez N, Rondon C, et al. Clavulanic acid can be the component in amoxicillin-clavulanic acid responsible for immediate hypersensitivity reactions. J Allergy Clin Immunol 2010;125(2):502-505 e502.

6. Torres MJ, Montanez MI, Ariza A, Salas M, Fernandez TD, Barbero N, et al. The role of IgE recognition in allergic reactions to amoxicillin and clavulanic acid. Clin Exp Allergy 2016;46(2):264-274.

7. Ariza A, Garzon D, Abanades DR, de los Rios V, Vistoli G, Torres MJ, et al. Protein haptenation by amoxicillin: high resolution mass spectrometry analysis and identification of target proteins in serum. J Proteomics 2012;77:504-520.

8. Larche M, Akdis CA, Valenta R. Immunological mechanisms of allergen-specific immunotherapy. Nat Rev Immunol 2006;6(10):761-771.

9. Landsteiner K, Jacobs J. Studies on the Sensitization of Animals with Simple Chemical Compounds. J Exp Med 1935;61(5):643-656.

10. Ariza A, Montanez MI, Pérez-Sala D. Proteomics in immunological reactions to drugs. Curr Opin Allergy Clin Immunol 2011;11(4):305-312.

11. Matzinger P. Tolerance, danger, and the extended family. Annu Rev Immunol 1994;12:991-1045.

12. Pichler WJ. Pharmacological interaction of drugs with antigen-specific immune receptors: the p-i concept. Curr Opin Allergy Clin Immunol 2002;2(4):301-305.

13. Pichler WJ, Beeler A, Keller M, Lerch M, Posadas S, Schmid D, et al.

Pharmacological interaction of drugs with immune receptors: the $\mathrm{p}$-i concept. Allergol Int 2006;55(1):17-25.

14. Antunez C, Martin E, Cornejo-Garcia JA, Blanca-Lopez N, R RP, Mayorga C, et al. Immediate hypersensitivity reactions to penicillins and other betalactams. Curr Pharm Des 2006;12(26):3327-3333.

15. Blanca M. The contribution of the side chain of penicillins in the induction of allergic reactions. J Allergy Clin Immunol 1994;94(3 Pt 1):562-563.

16. Coleman JW. Protein haptenation by drugs. Clin Exp Allergy 1998;28 Suppl 4:79-82.

17. Yvon M, Anglade P, Wal JM. Identification of the binding sites of benzyl penicilloyl, the allergenic metabolite of penicillin, on the serum albumin molecule. FEBS Lett 1990;263(2):237-240.

18. Jenkins RE, Yaseen FS, Monshi MM, Whitaker P, Meng X, Farrell J, et al. betaLactam antibiotics form distinct haptenic structures on albumin and activate drugspecific T-lymphocyte responses in multiallergic patients with cystic fibrosis. Chem Res Toxicol 2013;26(6):963-975.

19. Meng X, Jenkins RE, Berry NG, Maggs JL, Farrell J, Lane CS, et al. Direct evidence for the formation of diastereoisomeric benzylpenicilloyl haptens from 
benzylpenicillin and benzylpenicillenic acid in patients. $J$ Pharmacol Exp Ther 2011;338(3):841-849.

20. Whitaker P, Meng X, Lavergne SN, El-Ghaiesh S, Monshi M, Earnshaw C, et al. Mass spectrometric characterization of circulating and functional antigens derived from piperacillin in patients with cystic fibrosis. J Immunol 2011;187(1):200-211.

21. Garzon D, Ariza A, Regazzoni L, Clerici R, Altomare A, Sirtori FR, et al. Mass spectrometric strategies for the identification and characterization of human serum albumin covalently adducted by amoxicillin: ex vivo studies. Chem Res Toxicol 2014;27(9):1566-1574.

22. Mayorga C, Obispo T, Jimeno L, Blanca M, Moscoso del Prado J, Carreira J, et al. Epitope mapping of beta-lactam antibiotics with the use of monoclonal antibodies. Toxicology 1995;97(1-3):225-234.

23. Ariza A, Collado D, Vida Y, Montanez MI, Perez-Inestrosa E, Blanca M, et al. Study of protein haptenation by amoxicillin through the use of a biotinylated antibiotic. PLoS One 2014;9(3):e90891.

24. Ashwell JD, DeFranco AL, Paul WE, Schwartz RH. Antigen presentation by resting $B$ cells. Radiosensitivity of the antigen-presentation function and two distinct pathways of T cell activation. J Exp Med 1984;159(3):881-905.

25. Chu ET, Lareau M, Rosenwasser LJ, Dinarello CA, Geha RS. Antigen presentation by EBV-B cells to resting and activated T cells: role of interleukin 1. J Immunol 1985;134(3):1676-1681.

26. Sanchez-Gomez FJ, Gayarre J, Avellano MI, Pérez-Sala D. Direct evidence for the covalent modification of glutathione-S-transferase P1-1 by electrophilic prostaglandins: implications for enzyme inactivation and cell survival. Arch Biochem Biophys 2007;457(2):150-159.

27. Jiang L, He L, Fountoulakis M. Comparison of protein precipitation methods for sample preparation prior to proteomic analysis. J Chromatogr A 2004;1023(2):317-320. 28. Stamatakis K, Sanchez-Gomez FJ, Pérez-Sala D. Identification of novel protein targets for modification by 15-deoxy-Delta12,14-prostaglandin J2 in mesangial cells reveals multiple interactions with the cytoskeleton. J Am Soc Nephrol 2006;17(1):8998.

29. Garzon B, Gayarre J, Gharbi S, Diez-Dacal B, Sanchez-Gomez FJ, Timms JF, et al. A biotinylated analog of the anti-proliferative prostaglandin A1 allows assessment of PPAR-independent effects and identification of novel cellular targets for covalent modification. Chem Biol Interact 2010;183(1):212-221.

30. Thery C, Amigorena S, Raposo G, Clayton A. Isolation and characterization of exosomes from cell culture supernatants and biological fluids. Curr Protoc Cell Biol 2006; Chapter 3:Unit 322.

31. Pérez-Sala D, Oeste CL, Martinez AE, Carrasco MJ, Garzon B, Cañada FJ. Vimentin filament organization and stress sensing depend on its single cysteine residue and zinc binding. Nat Commun 2015;6:7287.

32. De Clerck LS. B lymphocytes and humoral immune responses in rheumatoid arthritis. Clin Rheumatol 1995;14 Suppl 2:14-18.

33. Karagiannis SN, Warrack JK, Jennings KH, Murdock PR, Christie G, Moulder K, et al. Endocytosis and recycling of the complex between CD23 and HLA-DR in human B cells. Immunology 2001;103(3):319-331.

34. Segura E, Guerin C, Hogg N, Amigorena S, Thery C. CD8+ dendritic cells use LFA-1 to capture MHC-peptide complexes from exosomes in vivo. J Immunol 2007;179(3):1489-1496.

35. Raposo G, Stoorvogel W. Extracellular vesicles: exosomes, microvesicles, and friends. J Cell Biol 2013;200(4):373-383.

36. Trajkovic K, Hsu C, Chiantia S, Rajendran L, Wenzel D, Wieland F, et al. Ceramide triggers budding of exosome vesicles into multivesicular endosomes.

Science 2008;319(5867):1244-1247. 
37. Fujita Y, Yoshioka Y, Ito S, Araya J, Kuwano K, Ochiya T. Intercellular communication by extracellular vesicles and their microRNAs in asthma. Clin Ther 2014;36(6):873-881.

38. McDonald MK, Tian Y, Qureshi RA, Gormley M, Ertel A, Gao R, et al. Functional significance of macrophage-derived exosomes in inflammation and pain. Pain 2014;155(8):1527-1539.

39. Bagai R, Valujskikh A, Canaday DH, Bailey E, Lalli PN, Harding CV, et al. Mouse endothelial cells cross-present lymphocyte-derived antigen on class I MHC via a TAP1- and proteasome-dependent pathway. J Immunol 2005;174(12):7711-7715. 40. Epperson DE, Pober JS. Antigen-presenting function of human endothelial cells. Direct activation of resting CD8 T cells. J Immunol 1994;153(12):5402-5412.

41. Limmer A, Ohl J, Kurts C, Ljunggren HG, Reiss Y, Groettrup M, et al. Efficient presentation of exogenous antigen by liver endothelial cells to CD8+ $T$ cells results in antigen-specific T-cell tolerance. Nat Med 2000;6(12):1348-1354.

42. Rothermel AL, Wang Y, Schechner J, Mook-Kanamori B, Aird WC, Pober JS, et al. Endothelial cells present antigens in vivo. BMC Immunol 2004;5:5.

43. Blanca-Lopez N, Perez-Alzate D, Ruano F, Garcimartin M, de la Torre V, Mayorga $\mathrm{C}$, et al. Selective immediate responders to amoxicillin and clavulanic acid tolerate penicillin derivative administration after confirming the diagnosis. Allergy 2015;70(8):1013-1019.

44. Nahm DH, Lee KH, Shin JY, Ye YM, Kang Y, Park HS. Identification of alphaenolase as an autoantigen associated with severe asthma. J Allergy Clin Immunol 2006;118(2):376-381.

45. Radauer C, Bublin M, Wagner S, Mari A, Breiteneder H. Allergens are distributed into few protein families and possess a restricted number of biochemical functions. J Allergy Clin Immunol 2008;121(4):847-852 e847.

46. Apostolovic D, Tran TA, Hamsten C, Starkhammar M, Cirkovic Velickovic T, van Hage M. Immunoproteomics of processed beef proteins reveal novel galactose-alpha1,3-galactose-containing allergens. Allergy 2014;69(10):1308-1315.

47. Campana S, De Pasquale C, Carrega P, Ferlazzo G, Bonaccorsi I. Crossdressing: an alternative mechanism for antigen presentation. Immunol Lett 2015;168(2):349-354.

48. Raposo G, Nijman HW, Stoorvogel W, Liejendekker R, Harding CV, Melief CJ, et al. B lymphocytes secrete antigen-presenting vesicles. $J$ Exp Med 1996;183(3):1161-1172.

49. Valadi H, Ekstrom K, Bossios A, Sjostrand M, Lee JJ, Lotvall JO. Exosomemediated transfer of mRNAs and microRNAs is a novel mechanism of genetic exchange between cells. Nat Cell Biol 2007;9(6):654-659.

50. Li T, Yan Y, Wang B, Qian H, Zhang X, Shen L, et al. Exosomes derived from human umbilical cord mesenchymal stem cells alleviate liver fibrosis. Stem Cells Dev 2013;22(6):845-854.

51. Zitvogel L, Regnault A, Lozier A, Wolfers J, Flament C, Tenza D, et al. Eradication of established murine tumors using a novel cell-free vaccine: dendritic cellderived exosomes. Nat Med 1998;4(5):594-600.

52. Janowska-Wieczorek A, Wysoczynski M, Kijowski J, Marquez-Curtis L, Machalinski B, Ratajczak J, et al. Microvesicles derived from activated platelets induce metastasis and angiogenesis in lung cancer. Int J Cancer 2005;113(5):752-760. 


\section{Figure legends.}

Figure 1. Haptenation of B-lymphocyte proteins by $\beta$-lactams. A. RPMI 8866 Blymphocytes were treated with $10 \mathrm{mg} / \mathrm{ml}$ of Penicillin G, $2.5 \mathrm{mg} / \mathrm{ml}$ of Amoxicillin or 0.5 $\mathrm{mg} / \mathrm{ml}$ of $\mathrm{AX}-\mathrm{B}$ for $16 \mathrm{~h}$ in RPMI1640 medium without serum. The concentrations of the antibiotic used were chosen depending on the sensitivity of the corresponding detection tool. Thirty micrograms of protein from cell lysates were analyzed by Western blot to detect the formation of the corresponding adducts or the biotin signal.

Representative band patterns of at least 3 different experiments for every condition are depicted. B. B-lymphocytes were incubated with $0.5 \mathrm{mg} / \mathrm{ml}$ AX-B for $16 \mathrm{~h}$ in RPMI1640 medium without serum. Cell preparations were incubated with Alexa-488-Streptavidin as described in Material and Methods to detect the biotin signal. Nuclear DNA was stained with DAPI. Scale bar, $10 \mu \mathrm{m}$.

Figure 2. Detection of AX-B- and AX-haptenated proteins in cells and conditioned medium. Cells were treated with $0.5 \mathrm{mg} / \mathrm{ml} A X-B(A)$ or $2.5 \mathrm{mg} / \mathrm{ml} A X(B)$ for $16 \mathrm{~h}$, as above in RPMI1640 medium without serum. Cells were harvested and conditioned medium collected and fractionated to analyze extracellular Membrane fraction, Extracellular vesicles and Soluble Proteins by SDS-PAGE and Western blot. Arrowheads mark biotin-positive bands that appear in all fractions. A polypeptide band that appears only in cell lysates is indicated with an asterisk. Blots were incubated with HRP-Streptavidin to detect the biotin signal, and with antibodies against the indicated proteins to confirm the accuracy of the fractionation procedure. Representative blots of at least 3 experiments are depicted. C. Soluble proteins present in the conditioned medium of cells treated with $0.5 \mathrm{mg} / \mathrm{ml}$ AX-B or $2.5 \mathrm{mg} / \mathrm{ml} \mathrm{AX}$ were analyzed for the formation of adducts with AX-B or AX by 2D SDS-PAGE as described in material and methods. Blots incubated with HRP-Streptavidin or anti-AX antibody A03.2 for biotin or AX adduct detection, respectively, and gels stained with Sypro Ruby for protein detection are depicted. Representative images for at least 3 experiments are shown. 
Numbers indicate spots that are positive both for $A X$ and $A X-B$ haptenation and were selected for MS analysis.

Figure 3. Validation of AX-B targets identified by MS by avidin affinity chromatography and immunoprecipitation. A. Soluble proteins isolated from conditioned medium of control and AX-B-treated cells were purified by avidin-based affinity chromatography and analyzed by SDS-PAGE. The presence of biotin and proteins of interest in the avidin-bound fraction (eluate) were assessed by incubation of the blots with HRP-Streptavidin or the corresponding antibodies. B. Proteins of interest were immunoprecipitated with the indicated antibodies. The immunoprecipitates were analyzed for the presence of a biotin signal associated with the corresponding proteins and of the proteins of interest with the indicated antibodies. In the case of Hsp70, TrueBlot $₫$ was used for detection. Representative blots from 3 different experiments are shown.

\section{Figure 4. Exosomes from AX-B-treated B-lymphocytes bearing haptenated} proteins are secreted by cells. A. Control and AX-B-treated cells were extensively washed to eliminate unreacted AX-B from the medium. Conditioned medium collected at $0\left(T_{0}\right)$ and $16 \mathrm{~h}\left(\mathrm{~T}_{16}\right)$ of an o/n incubation period was analyzed for biotin positive polypeptides by SDS-PAGE and Western blot. A representative blot from three different experiments is shown. B. Exhaustively washed AX-B-treated cells were then cultured in serum free medium for an additional $24 \mathrm{~h}$ period. Both, cells and conditioned medium were collected and fractionated to analyze the indicated fractions. Blots were incubated with HRP-Streptavidin to detect the biotin signal, and with the indicated antibodies to assess the accuracy of the fractionation. Representative blots from three experiments are depicted. C. EVs isolated from conditioned medium of Blymphocytes were observed by EM as described in Materials and Methods. Typical vesicle shapes are depicted in the representative micrographs shown. Scale bar, 200 
nm. D. B-lymphocytes were treated with or without AX-B for $16 \mathrm{~h}$, the unreacted excess of AX-B washed out and the cells treated with $10 \mu \mathrm{M}$ C6 ceramide, $10 \mu \mathrm{M}$ dihydroceramide C6 or $5 \mu \mathrm{M}$ GW4869 for additional $24 \mathrm{~h}$. The EVs fraction from conditioned medium was analyzed by Western blot to detect the biotin signal, as well as ICAM-1 and HSP70 as exosome markers. Representative blots from three different experiments are shown. E. B-lymphocytes were treated in absence or presence of 0.5 $\mathrm{mg} / \mathrm{ml} \mathrm{AX}-\mathrm{B}$, the unreacted antibiotic was exhaustively washed and the newly secreted EVs, isolated as described in Material and Methods. The complete EVs fraction was precipitated and processed to analyze biotin positive proteins by 2D SDS-PAGE. A replicate sample was used to detect total protein by Sypro Ruby staining. The AX-B targets previously identified in the extracellular soluble protein fraction were located in the blots and gels of EVs fraction and identified by MS. Spots excised are numbered in the figure. Spots 2, 3 and 4 correspond to a-enolase, EF-2 and Hsp70, respectively.

Figure 5. Secreted EVs bear and deliver AX-B-modified proteins to target cells. $A$. Secreted EVs isolated from conditioned medium of B-lymphocytes treated with or without $0.5 \mathrm{mg} / \mathrm{ml}$ AX-B were incubated with $10 \mathrm{~nm}$ Streptavidin-gold particles and visualized by EM as described in Materials and Methods. Particles bound to vesicles are indicated by arrowheads. Representative images from three different experiments are shown. Scale bar, $200 \mathrm{~nm}$. B. B-lymphocytes were treated with or without 0.5 $\mathrm{mg} / \mathrm{ml} \mathrm{AX-B}$ and the secreted EVs isolated as described in Material and Methods. Control EVs were then treated with $0.5 \mathrm{mg} / \mathrm{ml} \mathrm{AX}-\mathrm{B}$ in vitro for $16 \mathrm{~h}$ and compared with EVs secreted by AX-B-treated cells by SDS-PAGE. Anti-ICAM-1 was used as an exosome marker. The biotin signal was densitometered and represented to compare the band patterns of biotin positive polypeptides. Dotted line, in vitro AX-B labeled EVs; solid line, EVs obtained from AX-B-treated cells. Representative blots from three different experiments are shown. C. Secreted EVs from control or AX-B-treated Blymphocytes were isolated and labeled with FITC and TXR-Streptavidin. Endothelial 
cells were then incubated with either EVs preparation for $3 \mathrm{~h}$, fixed and stained with anti-RhoGDI. Cells were observed by fluorescence confocal microscopy to analyze the presence of EVs internalized by endothelial cells. Representative images of three experiments are depicted. Scale bars, $20 \mu \mathrm{m}$. 
Table 1. MS identification of selected AX-B-modified proteins from extracellular Soluble Proteins and EVs fractions.

\begin{tabular}{|c|c|c|c|c|c|c|c|}
\hline Fraction & SPOT & $\begin{array}{c}\text { Acc. } \\
\text { Number }\end{array}$ & Gene name & Score & $\begin{array}{l}\text { Limit } \\
\text { score }\end{array}$ & MW & $\begin{array}{l}\text { Isoelectric } \\
\text { point }\end{array}$ \\
\hline $\begin{array}{l}\text { Soluble } \\
\text { protein }\end{array}$ & 1 & P60709 & $\beta$-actin (ACTB) & 351 & 59 & 40536 & 5.55 \\
\hline $\begin{array}{l}\text { Soluble } \\
\text { protein }\end{array}$ & 2 & P07437 & $\beta$-tubulin (TUBB) & 246 & 59 & 50096 & 4.75 \\
\hline $\begin{array}{l}\text { Soluble } \\
\text { protein }\end{array}$ & 3 & Q71U36 & $\begin{array}{c}\alpha-1 A \text { Tubulin } \\
\text { (TBA1A) }\end{array}$ & 317 & 59 & 46797 & 4.96 \\
\hline $\begin{array}{l}\text { Soluble } \\
\text { protein }\end{array}$ & 4 & Q53GZ6 & HSP70 & 157 & 59 & 71083 & 5.28 \\
\hline $\begin{array}{l}\text { Soluble } \\
\text { protein }\end{array}$ & 5 & P13639 & EF-2 & 100 & 59 & 96246 & 6.41 \\
\hline $\begin{array}{l}\text { Soluble } \\
\text { protein }\end{array}$ & 6 & P06733 & $\begin{array}{c}\alpha \text {-enolase } \\
\text { (ENOA) }\end{array}$ & 162 & 59 & 47453 & 7.01 \\
\hline EVs & 1 & P08133-2 & $\begin{array}{l}\text { Isoform } 2 \text { of } \\
\text { Annexin A6 }\end{array}$ & 73 & 59 & 72720 & 5.42 \\
\hline EVs & 2 & P06733 & $\begin{array}{c}\alpha \text {-enolase } \\
\text { (ENOA) }\end{array}$ & 83 & 59 & 47453 & 7.01 \\
\hline EVs & 3 & P13639 & EF-2 & 195 & 59 & 96246 & 6.41 \\
\hline EVs & 4 & Q53GZ6 & HSP70 & 69 & 59 & 71083 & 5.28 \\
\hline EVs & 5 & P50990 & $\begin{array}{l}\text { T-complex } \\
\text { protein } 1 \theta\end{array}$ & 139 & 59 & 60153 & 5.42 \\
\hline
\end{tabular}

Results obtained for the identification of AX-B modified proteins from extracellular Soluble Proteins and EVs fractions picked from 2D Sypro Ruby-stained gels. The fraction, number of the spot, accession number, gene name, experimental score, limit score, molecular weight and isoelectric point are included. Limit score refers to the minimum score for an identification to be considered positive by MASCOT software 2.3 analysis. 
Figure 1.
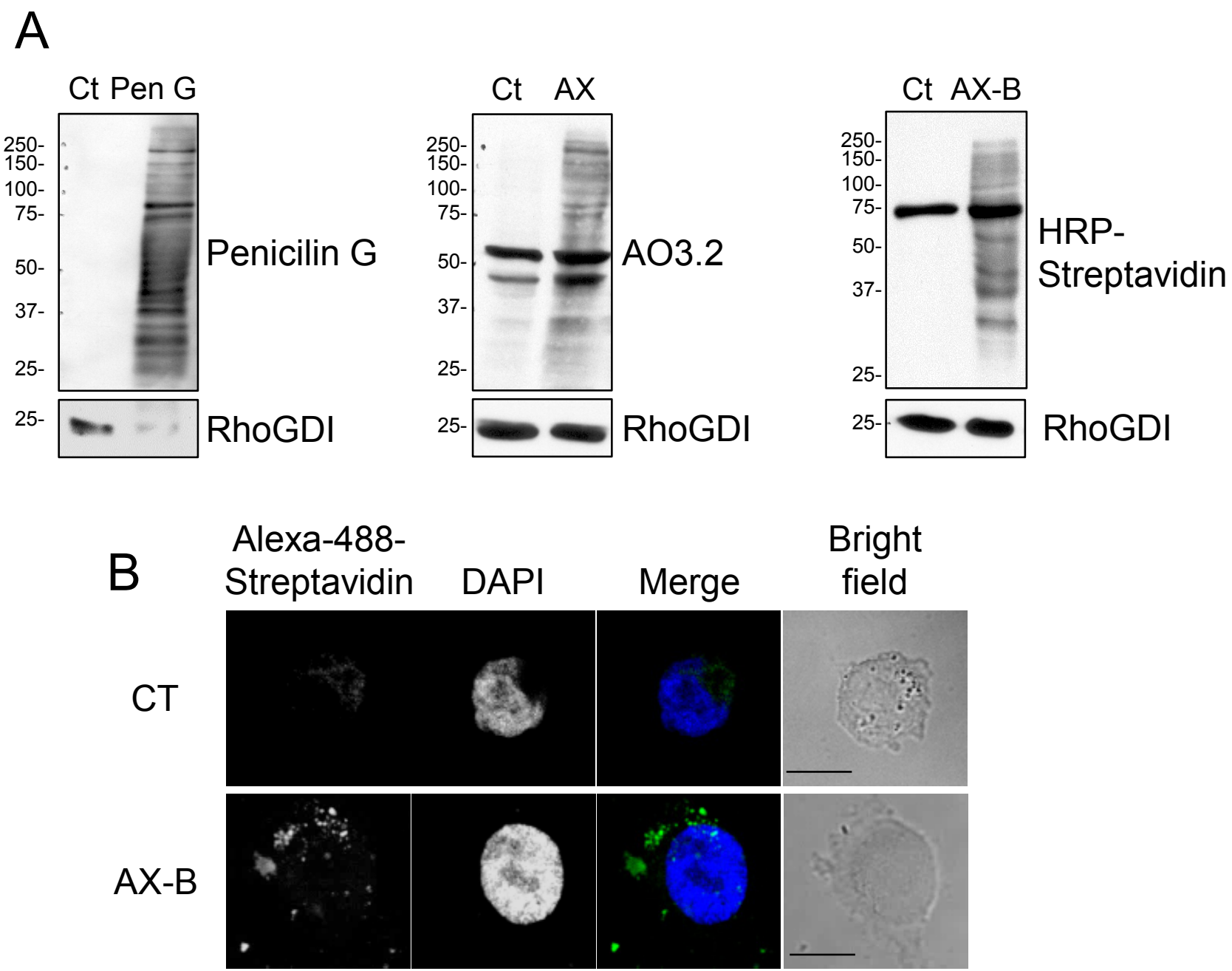

Bright

field
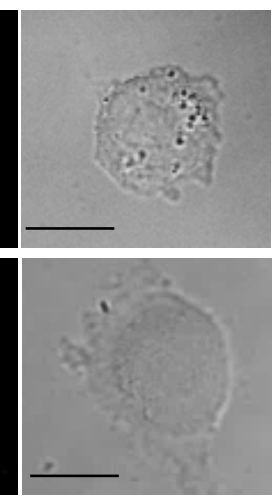
Figure 2.
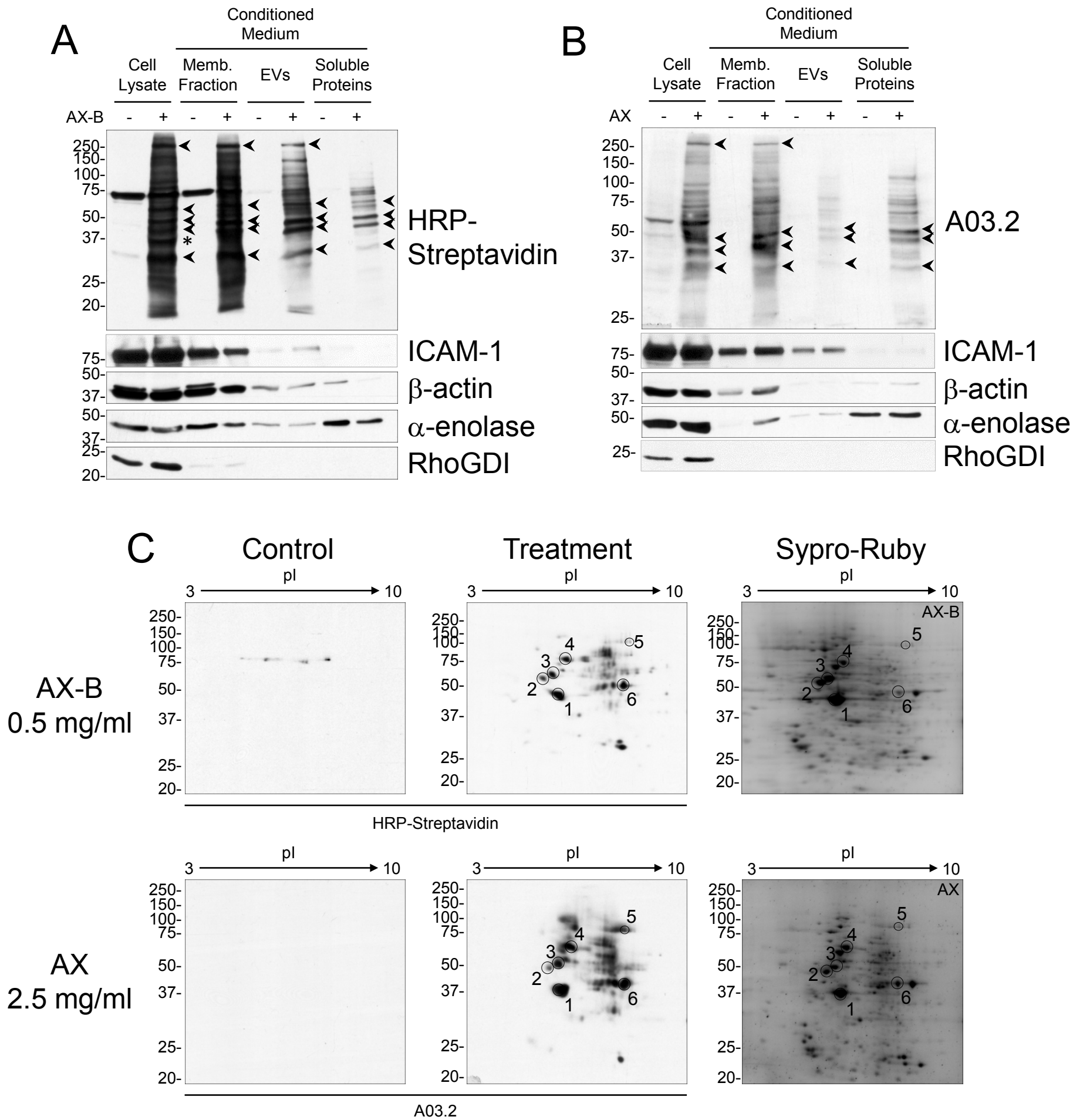
Figure 3.

A

Soluble Proteins Soluble Proteins $\mathrm{Ct}$

AX-B $0.5 \mathrm{mg} / \mathrm{ml}$
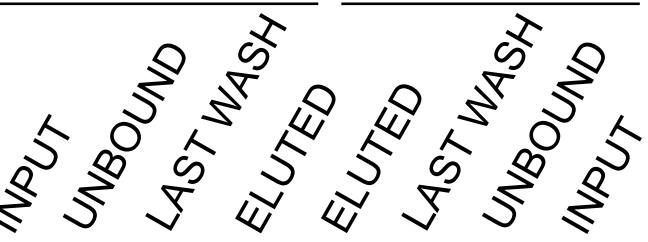

250

$150-$

100-

75-

$50-$

37-

25-

100

75

75

$50-$

$-$

$37-$

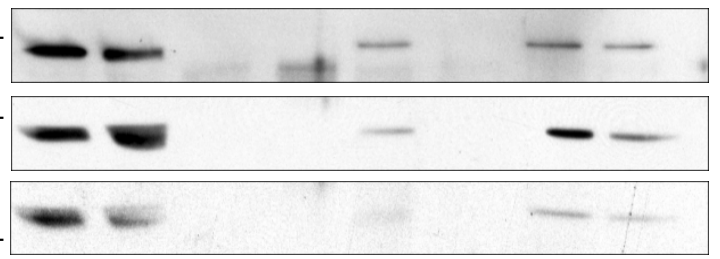

HRP-

Streptavidin

EF-2

HSP70

$\alpha$-enolase

$\beta$-actin

B

Soluble Proteins Soluble Proteins

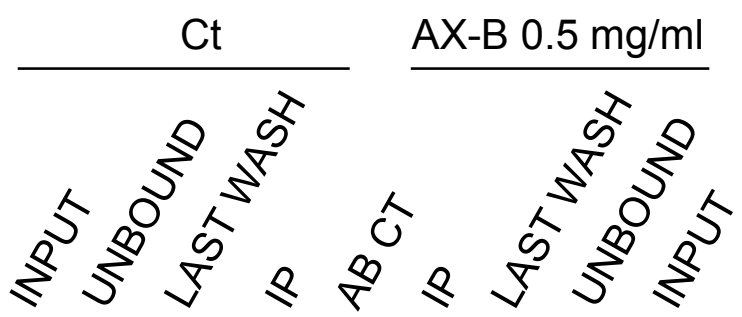

IP: anti-EF-2

IP: anti-HSP70
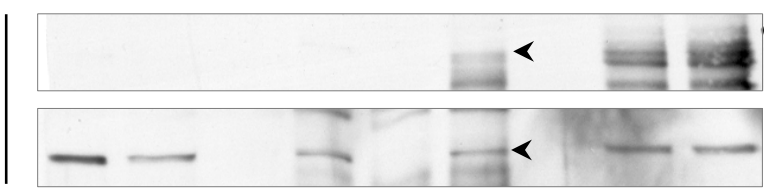

HRP-Streptavidin HSP70

HRP-Streptavidin

IP: anti- $\alpha$-enolase

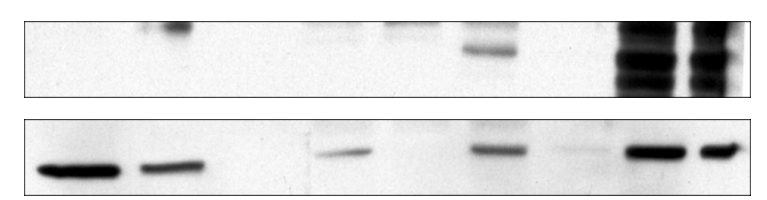

$\alpha$-enolase

HRP-Streptavidin

EF-2

a-enolase 
Figure 4.

A

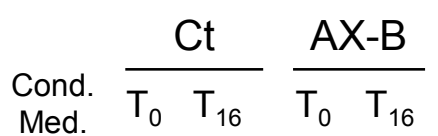

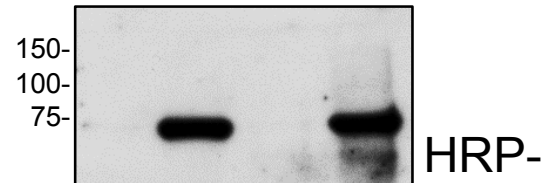

50- . Streptavidin

C

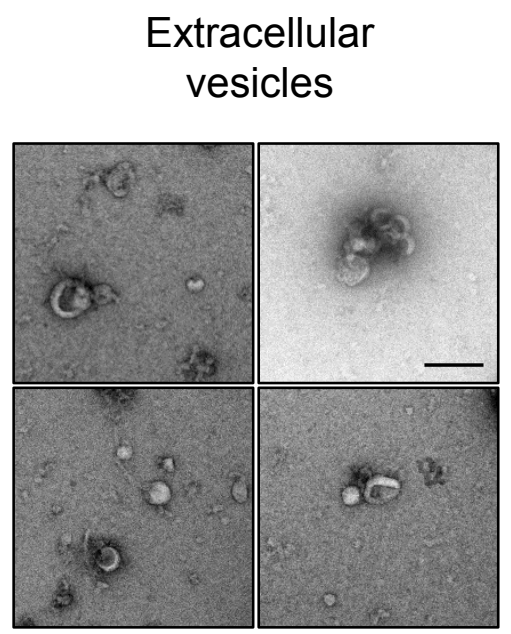

HRP-Streptavidin

E

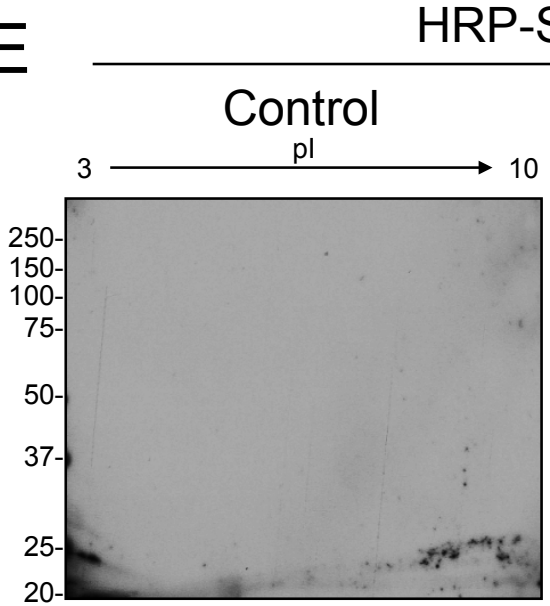

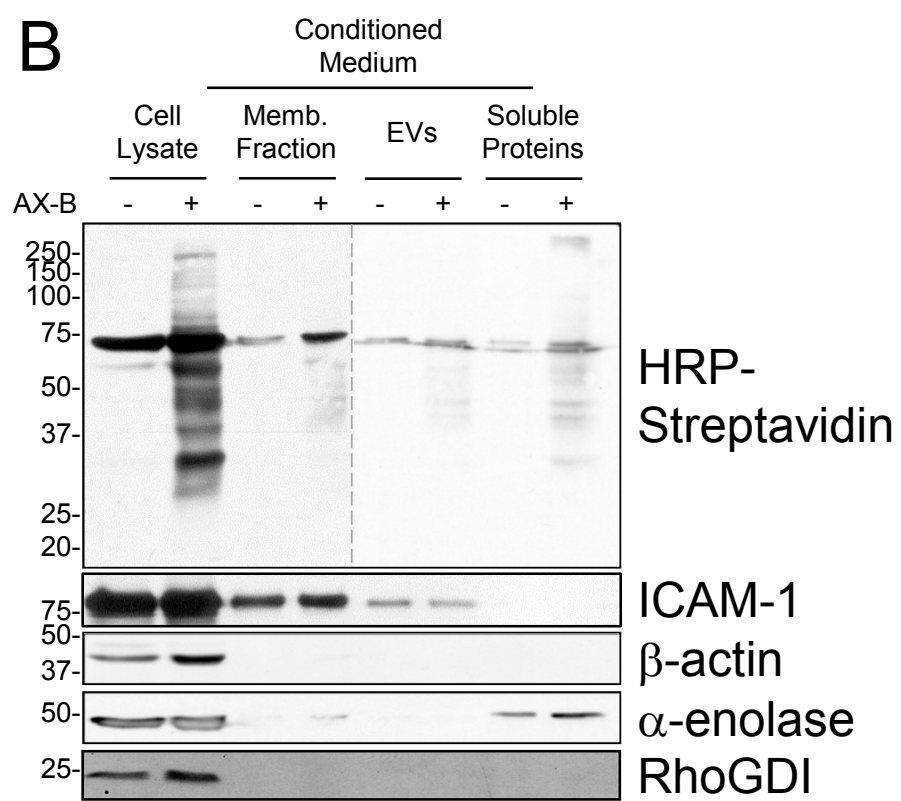

AX-B

$0.5 \mathrm{mg} / \mathrm{ml}$

D

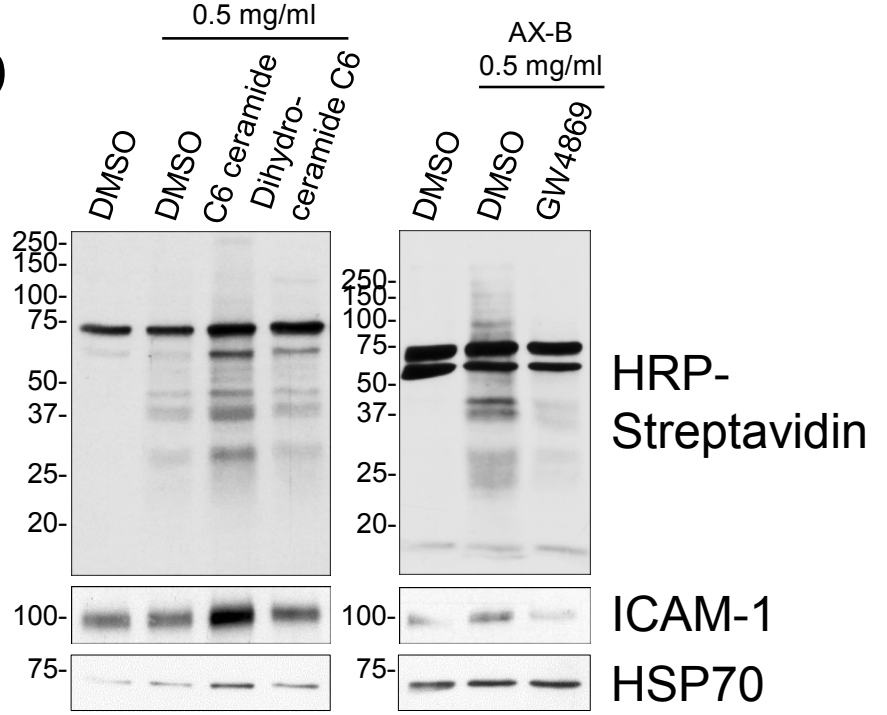

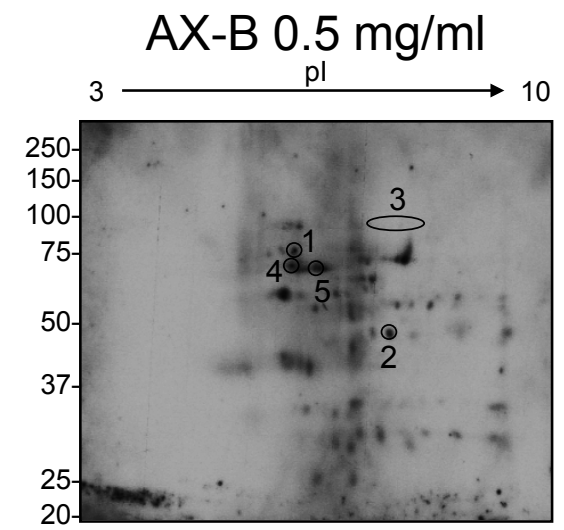

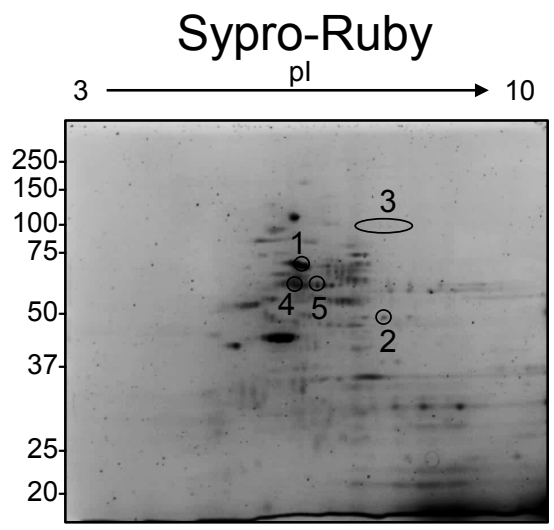


Figure 5.

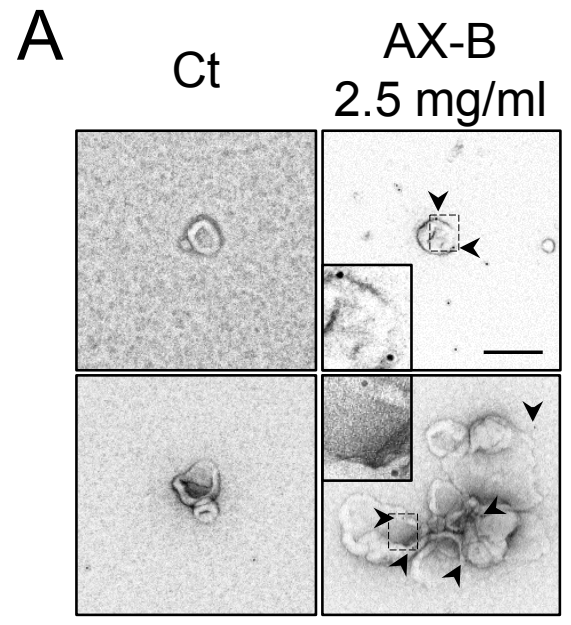

B $\frac{\text { In vitro }}{\text { CT AX-B }} \frac{\text { Cells }}{\text { CT AX-B }}$

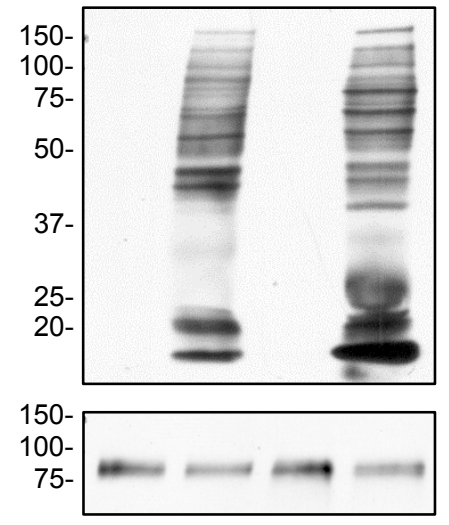

HRP-

Streptavidin

ICAM-1

TXR-

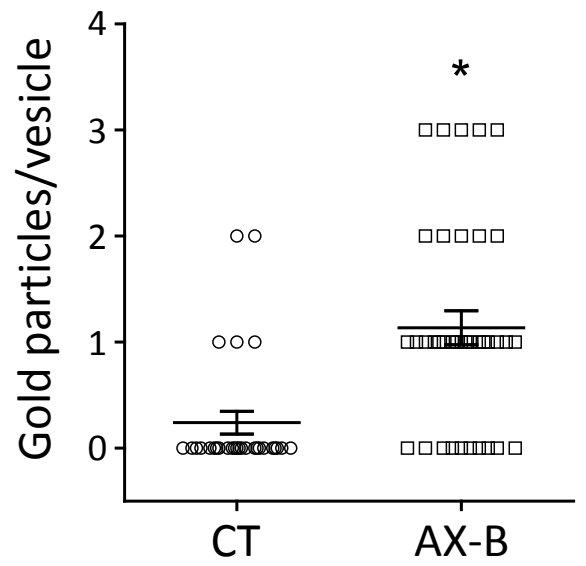

C

FITC Streptavidin

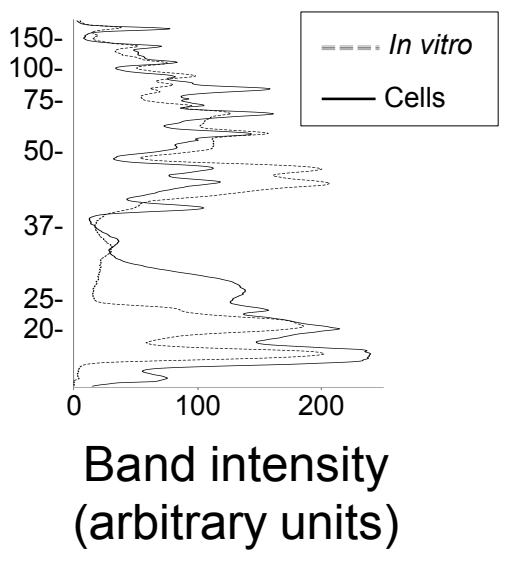

RhoGDI

Merge

AX-B
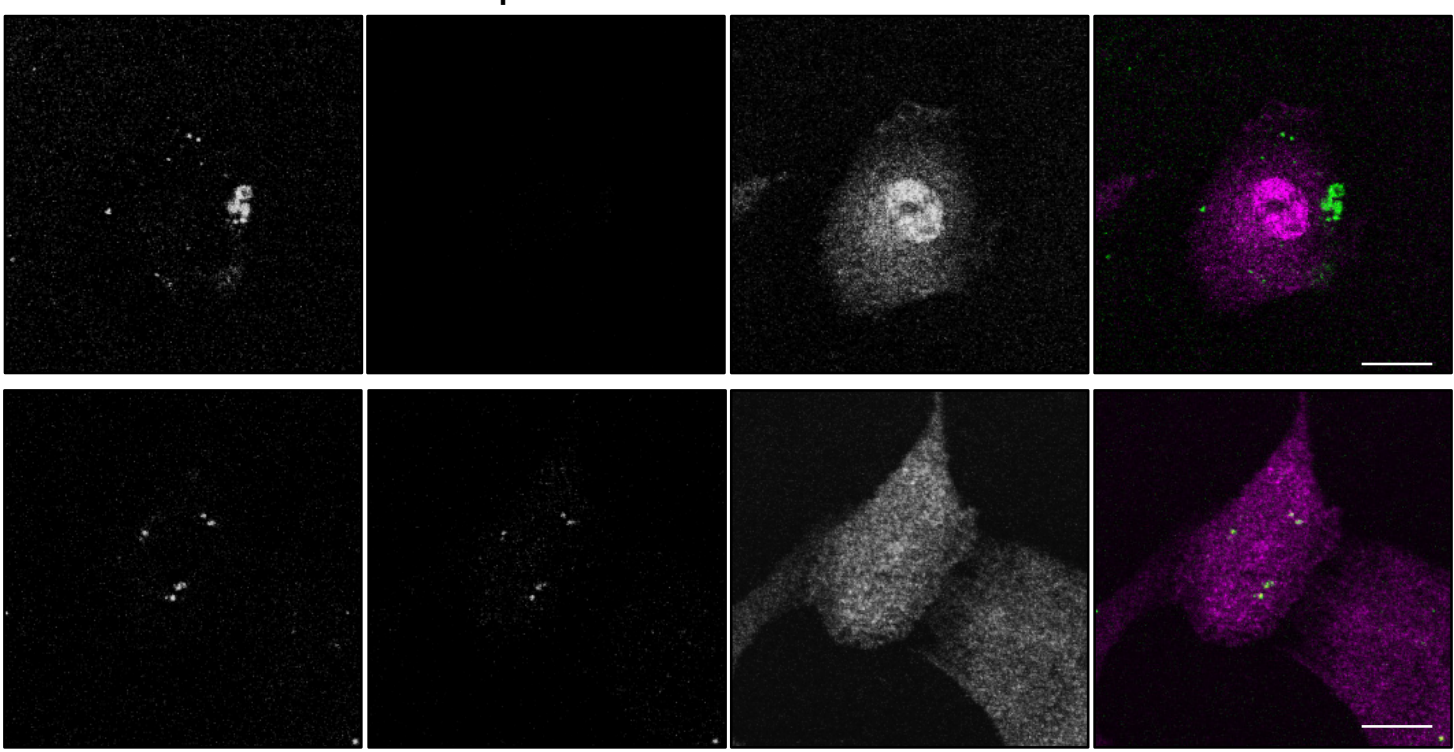